\title{
Öğrencilerin Sosyal Medya Tutumları ve Yalnızlık Algıları: Lise ve Ön lisans Öğrencileri Üzerine Bir Araştırma
}

\author{
Mehmet Gökhan GENEL ${ }^{1}$
}

Öz

Sosyal medya platformları günümüzün en belirleyici bilgi otobanları olmasının yanı sıra özellikle $Z$ kuşağı diye tabir edilen genç neslin bilgilenme, deneyimleme, eğlence ve zaman geçirme mecraları arasında yer almaktadır. Bu perspektifle bakıldığında yeni neslin iletişim araçları olan sosyal medya ortamları bir yönüyle çağın gerçekliğini yansıtırken diğer yönüyle de bahsi geçen neslin sosyalleşme/asosyalleşme ve yalnızlaşma gibi problemlere ilişkin önemli bir tartışmayı da gündeme getirmiştir. Bu yaklaşım çerçevesinde çalışma, öğrencilerin sosyal medya tutumları (sosyal yetkinlik, paylaşım ihtiyacı, öğretmen ile iletişim ve sosyal izolasyon) ve yalnızlık algııları arasındaki ilişkilerin incelenmesini amaçlamaktadır. Değişkenlerin ölçülmesi amacıyla Sosyal medya tutum ölçeği ve UCLA Yalnızlık ölçeği kullanılmıştır. Çalışma 2020-2021 öğretim yilında Erzincan İlinde lise ve ön lisans düzeyinde öğrenim gören 478 öğrenci üzerinde gerçekleștirilmiştir. Veri seti SPSS 22 istatistik paket programında analiz edilmiştir. Korelasyon bulguları, sosyal yetkinlik tutumu ile yalnızlık arasında olumsuz bağlantı olduğunu göstermektedir. Benzer şekilde sosyal izolasyon tutumunun yalnızlık ile negatif ilişkili olduğu sonucuna ulaşılmışıı. Bu sonuçların tersine paylaşım ihtiyacı yalnızlık ile pozitif ilişkilidir. Yani, paylaşım ihtiyacını vurgulayan öğrencilerin yalnızlık algısı daha yüksektir. Bu çalışmada, sosyal medya tutumlarından ögretmen ile ilişki alt boyutunun yalnızlık ile ilişkili olmadığı sonucuna ulaşılmıştır. Araştırma sonuçları bireylerin yalnızlık algılarının sosyal medyaya ilişkim tutum ve algılarını şekillendirdiğine işaret etmektedir.

Anahtar Kelimeler: Sosyal medya, Paylaşım ihtiyacı, Sosyal yetkinlik, Sosyal izolasyon, Yalnızlık

\section{Social Media Attitudes and Perceptions of Loneliness of Students: A Study on High School and Associate Degree Students}

\begin{abstract}
In addition to being the most determinant information highways of today, social media platforms are among the information, experience, entertainment and time spending channels of the young generation, the generation $Z$ in particular. When viewed from this perspective, social media environments, which are the communication tools of the new generation, reflect the reality of the age in one aspect and have brought an important discussion on the problems such as socialization/asocialization and isolation of the aforementioned generation on the other. Within the framework of this approach, the study aims to examine the relationships between students' social media attitudes (social competence, sharing need, communication with teachers and social isolation) and their perceptions of loneliness. Social media attitude scale and UCLA Loneliness Scale were used to measure the variables. The study was conducted on 478 high schools and associate degree students in Erzincan in the 2020-2021 academic year. The data set was analyzed in SPSS 22 statistical package program. Correlation findings show that there is a negative connection between social competence attitude and loneliness. Similarly, it was concluded that social isolation attitude was negatively related to loneliness. Contrary to these results, the need for sharing is positively associated with loneliness. That is, students who emphasize the need for sharing have a higher perception of loneliness. In this study, it was concluded that the relationship with the teacher sub-dimension of social media attitudes is not related to loneliness. Research results indicate that individuals' perceptions of loneliness shape their attitudes and perceptions of social media.
\end{abstract}

Key Words: Social media, Sharing need, Social competence, Social isolation, Loneliness

\section{Atıf İçin / Please Cite As:}

Genel, M. G. (2021). Öğrencilerin sosyal medya tutumları ve yalnızlık alg1ları: lise ve ön lisans öğrencileri üzerine bir araştırma. Manas Sosyal Araştırmalar Dergisi, 10(4), 2148-2159.

Geliş Tarihi / Received Date: 05.03.2021

Kabul Tarihi / Accepted Date: 03.06.2021

\footnotetext{
${ }^{1}$ Doç. Dr. - Yalova Üniversitesi Sanat ve Tasarım Fakültesi, gokhan.genel@gmail.com

(D) ORCID: 0000-0002-7681-1737
} 


\section{Giriş}

20. Yüzyl'’n son çeyreğinde insanlık, bilişim teknolojileri dolayımında yeni iletişim mecralarıyla tanışmış ve tedrici olarak eskiye ait konvansiyonel medya ortamlarından uzaklaştı̆̆ görülmüştür. Yeni medya diye tabir edilen bu ortamlar sınır tanımaksızın dünyayı sanal ağlarla birbirine bağlamış ve McLuhan'ın da dediği gibi dünyayı "evrensel bir köye” dönüştürmeye başlamıştır. Bu yeni nesil ortamlardan biri olan sosyal medya platformaları toplumun tüm kesimlerince benimsenmesine karşın en çok da genç yetişkinler tarafindan yaygın olarak kullanıldığını yapılan araştırmalar ortaya koymaktadır. We are social 2020 mobil, internet ve sosyal medya kullanıcı istatistiklerini içeren ikinci çeyrek raporuna göre, dünya nüfusunun \%59'u internet kullanıc1s1, \%66's1 mobil kullanıc1s1 ve \%49'u ise sosyal medya kullanıcısıdır. Aynı rapora göre, Facebook, Youtube ve Instagram kullanıcı sayısı en yüksek sosyal medya platformlarıdır. Facebook kullanıcılarının \%56'sı, Instagram kullanıcılarının ise \%64’ü 18-34 yaş aralı̆ı̆nda yer almaktadır.

Sosyal medyanın sağladığı yüksek kişilerarası bağlantıya rağmen, "genç yetişkinlerin diğer yaş gruplarından daha yalnız olması ve mevcut neslin şimdiye kadarki en yalnız nesil olması şaşırtıcıdır" (Pittman ve Reich, 2016, s. 155). Yalnızlı, dijitalleşen dünyada en önemli pandemilerden biri haline gelmiştir. Yalnızlık sorunu, sosyal medya kullanımının en yüksek seviyede olduğu toplumlarda da devam etmektedir. Örneğin, Twenge (2018, s. 15) tarafindan ABD' de gençlerin tutumları izlenerek yürütülen boylamsal bir araştırma özellikle 2007 sonrasında artan depresyon ve yalnızlğga işaret etmektedir. Ruh Sağllğı Vakfi tarafindan yaptırılan bir çalışmaya göre, İngiliz yetişkinlerin \%48'i Birleşik Krallık'taki insanların zaman ilerledikçe yalnızlaştıklarına inanıyor, \%45'i bazen kendisini yalnız hissediyor ve \%42'si yalnızlığa bağlı olarak kendisini depresyonda hissediyor (Griffin, 2010, s. 35).

Araştırmalar, sanal dünyada zamanlarını geçiren bireylerin gerçek hayatlarında daha yalnız olduklarını göstermektedir (Örn. Kubey, Lavin ve Barrows, 2001, s. 366; Shaw ve Gant, 2002, s. 157). Sanal dünyada geçirilen zaman arttıkça yüz yüze ilişkilere ve gerçek sosyal bağlantılara harcanan zaman azalmaktadır. Bu ise sosyal izolasyona neden olmakta ve bireylerde yalnızlı̆ı artırmaktadır (Chou ve Hsiao, 2000, s. 65). Benzer şekilde Kim, LaRose ve Peng (2009, s. 454), sanal ortamların bireyleri gerçek sosyal bağlamlardan uzaklaştırıp yalnızlık algısını güçlendirdiğini ifade etmiştir.

Hunt, Marx, Lipson ve Young (2018, s. 763) tarafindan sosyal medya kullanımının düşük iyi oluşla ilişkilendiren korelasyonel araştırmaların genişliği göz önüne alınarak sosyal medyanın bu ilişkide oynadı̆̆ı potansiyel nedensel rolü araştırmak için deneysel bir çalışma yürütülmüştür. Bir haftalık temel izlemeden sonra, Pennsylvania Üniversitesi'ndeki 143 lisans öğrencisi, Facebook, Instagram ve Snapchat kullanımını platform başına, günde 10 dakika ile sınırlandırmak (sınırlı kullanım grubu) veya sosyal medyayı üç hafta boyunca her zamanki gibi kullanmak (kontrol grubu) üzere rastgele atanmıştır. Araştırma bulguları, sınırlı kullanım grubunda, kontrol grubuna kıyasla üç hafta boyunca yalnızlık ve depresyonda önemli düşüşler olduğunu göstermiştir. Çalışma sonuçları, sosyal medya kullanımının günde yaklaşı 30 dakika ile sınırlandırılmasının iyi oluşta önemli bir iyileşmeye yol açabileceğini güçlü bir biçimde göstermektedir. Tromholt (2016, s. 661) tarafindan Danimarka'da yürütülen benzer bir çalışmada 1095 katıllımcı iki gruba ayrılmıştır. Bir hafta süre ile sosyal medya kullanımına ara veren grubun iyi oluş düzeyi artmış ve pozitif bir ruh hali sergilemiş̦tir.

16-25 yaş arası 528 sosyal medya kullanıcı üzerinde yapılan kapsamlı bir çalışma, katıllımcılardan \%60'ının sosyal medyanın insanları bencilleştirdiği (sık kullananlarda bu oran artmaktadır), \%58'inin sosyal medyanın insanı yalnızlaştırdığı, \%71.2'sinin sosyal medyada ilişkilerin son derece yüzeysel olduğu düşüncesinde olduğunu raporlamıstır (Bozkurt, 2018, s. 10). Aynı çalışmada katılımcıların \%36,2'si sosyal medya kullanımının kendi mutsuzluklarını artırdığını ifade etmişlerdir. Dürtüsellik ile yalnızlık arasındaki ilişkide sosyal medya kullanımının aracı rolünün incelendiği bir çalışmada sosyal medya kullanımının yalnızlı̆̆1 doğrudan artırdığı ortaya konmuştur (Savc1 ve Aysan, 2016, s. 106).

Sosyal medya (Facebook-Instagram) kullanımının hem doğrudan hem de dolaylı olarak depresyon belirtileriyle pozitif yönde ilişkili olduğu bulunmuştur (Örn. Donnelly ve Kuss, 2016, s. 4; Tandoc, Ferrucci ve Duffy, 2015, s. 143). Facebook kullanımının zaman içinde daha düşük yaşam memnuniyeti öngördüğünü bulmuşlardır (Kross, Verduyn, Demiralp, Park, Lee, Lin, ... ve Ybarra, 2013, s. 4). Aynı çalısmada, Facebook kullanımı ile yalnızlık arasında zayıf pozitif korelasyon bulunmuştur Diğer taraftan araştırmalar, sosyal medya kullanımı ile depresif belirtiler arasındaki ilişkide sosyal karşılaştırmalar ve akran 
kıskançlı̆̆ının önemli bir rol oynadığını göstermiştir (Steers, Wickham ve Acitelli, 2014, s. 723; Tandoc, Ferrucci ve Duffy, 2015, s. 143; Verduyn, Lee, Park, Shablack, Orvell, Bayer, ... ve Kross, 2015, s. 486).

Son yıllarda sosyal medya ağlarının hızlı büyümesi, insanların düşüncelerini ve deneyimlerini paylaşarak başkalarıyla bağlantı kurmasını sağlayarak ilişki geliştirme için harika bir firsat oluşturmuştur. Sosyal medya ağlarının, insanlara sosyal ilişki kurmak için önemli bir kaynak sunduğu düşünülebilir. Ancak sözü edilen araştırma sonuçları, sosyal medya kullanımının bireylerin sosyal izolasyonlarını artırırken, iyi oluşlanını baltalayabileceğini göstermektedir.

Literatürdeki önemli tartışmalardan biri de sosyal medya kullanımı ile yalnızlık arasındaki ilişkinin yönüdür. Daha depresif veya yalnız bireylerin, başkalarıyla bağlantı kurmak için sosyal medyayı daha fazla kullanması oldukça olasıdır. Young ve Roger (1998, s. 25), yalnızlı̆̆ın ve sosyal izolasyonun bireyleri gerçek dünyadan uzaklaştırıp sanal ortamlara yaklaştırdığını vurgular. Literatürde, sosyal medya bağımlılı̆̆1 ile iş yalnızlı̆̆ı arasında pozitif korelasyon olduğunu gösteren çalışmalar bu görüşü desteklemektedir. Diğer taraftan, daha düşük öz saygıya veya daha zayıf benlik imajına sahip bireylerin daha fazla etkileşimde bulunma eğiliminde olmaları mümkündür (Hunt vd., 2018, s. 763). Facebook'un daha yüksek kullanımının, düşük benlik sayg1sı (Kalpidou, Costin ve Morris, 2011, s. 183) ve daha fazla yalnızlı (Song, ZmyslinskiSeelig, Kim, Drent, Victor, Omori ve Allen, 2014, s. 446) ile ilişkili olduğu bulunmuştur. Yang ve Tung (2007, s. 79) internet bağımlılı̆̆1 ve kişilik özellikleri arasındaki ilişkinin anlamlı olduğu, internet bağımlısı olan bireylerin olmayanlara göre daha düşük özgüvene ve depresif duygulara sahip olduğu sonucuna ulaşmıştır. Bununla birlikte Forest ve Wood (2012, s. 300), daha düşük özgüven ve daha zayıf benlik saygısına sahip kişilerin sosyal medyayı kullanma şeklinin, potansiyel sosyal faydalarından yararlanmalarını engelleyebileceğini öne sürmektedir.

Sosyal medya ve yalnızlık arasındaki ilişkileri inceleyen çalışmalarla elde edilecek bulgular, sosyal medya araçlarının gelişmesine bağlı olarak artan kişilerarası bağlantı imkânlarına rağmen bireylerin yalnızlaşması olgusunun derinlemesine anlaşılmasına katkı sağlayabilir. Bu çalışmada, sosyal medya tutumları ile yalnızlık arasındaki ilişkilerin öğrenciler üzerinde incelenmesi amaçlanmaktadır. Yalnızlık algıları bireylerin bazı tutum ya da davranışsal stratejileri benimseme olasılı̆̆ını arttırabilir. Ergenler üzerinde yapılan bir çalışma yalnızlık düzeyi düşük olan ergenlerin sosyal gruplara dahil olma şeklindeki davranışsal stratejileri kullanmalarının daha olası olduğunu ve çevrimiçi olmayı yalnızlıkla başa çıkmada bir araç olarak gördüklerini göstermiştir (Roshoe ve Skomski, 1989, s. 947). Literatüre dayalı olarak aşağıdaki hipotezler oluşturulmuştur.

H1: Sosyal medya tutumlarından sosyal yetkinlik ile yalnızlık arasında ilişki vardır.

H2: Sosyal medya tutumlarından paylaşım ihtiyacı ile yalnızlık arasında ilişki vardır.

H3: Sosyal medya tutumlarından öğretmen ile iletişim ile yalnızlık arasında ilişki vardır.

H4: Sosyal medya tutumlarından sosyal izolasyon ile yalnızlık arasında ilişki vardır.

\section{Yöntem}

Çalışmada nicel araştırma yöntemlerinden ilişkisel tarama modelinden faydalanılmış ve ölçme aracı olarak da anket metodu uygulanmıştır. İlişkisel tarama metodunda, iki veya daha fazla sayıda mevcut olan değişken arasında, birlikte artan veya birlikte azalan şeklinde oluşabilecek bir değişimin gerçekleşip, gerçekleşmediği başat önem arz etmektedir. Değişimin olması halinde, değişimin ivmesini tespit etmeye yönelik bir araştırma modeli olarak tanımlanan ilişkisel tarama yöntemi, değişkenlerin birlikte hareket etmesi noktasına odaklanmaktadır. Bu çalışmada öğrencilerin sosyal medya tutumları ve yalnızlık algısı bağlamında gelişen davranış şekilleri araştırılmıştır. Anketler, Erzincan ilinde lise ve önlisans düzeyinde eğitim gören kız ve erkek öğrencilerin sosyal medyayı kullanma alışkanlıkları ve yalnızlık hissiyatlarına dair tutumlarını ölçmek adına uygulanmıştır. Bu hedef doğrultusunda rastgele örnekleme yöntemi kullanılarak seçilen öğrencilere, kişisel bilgi formları ile birlikte sosyal medyayı kullanım alışkanlıklarına ve yalnızlık algılarına dair yönelik sorular yöneltilerek, sosyal medya tutum ölçeği uygulanmıştır. Araştırmanın değişkenlerini ölçen anket formu, öğrencilere yüz yüze uygulanarak veri toplanılmıştır.

\section{Evren - Örneklem}

Çalışma, 2020-2021 öğretim yılında Erzincan İlinde lise ve önlisans düzeyinde öğrenim gören 478 öğrenci üzerinde gerçekleştirilmiştir. Araştırmanın değişkenlerini ölçen anket formu, öğrencilere yüz yüze uygulanarak veri toplanılmıştır. Anket uygulanırken, ankete katılımın gönüllü olduğu ve elde edilen 
verilerin sadece bilimsel bir çalışma için kullanılacağı belirtilmiştir. Çalışmada öncelikle demografik değişkenler incelenmiştir. Katıllımcıların 252'sinin lise öğrencisi (\%52,7) ve 226 tanesinin ön lisans öğrencisi $(\% 47,3)$ olduğu görülmüştür. Katılımcıların 302'si erkek $(\% 63,2)$ ve 176's1 $(\% 36,8)$ kadındır. Katılımcıların yaş ortalaması yaklaşık 18'dir.

\section{Veri Toplama Araçları}

Çalışmada Otrar ve Argın (2014; 2015) tarafindan geliştirilen sosyal medya tutum ölçeği kullanılmıştır. Ölçeğin güvenilirlik Cronbach Alpha değeri 0,852 olarak hesaplanmıştır. 4 alt boyut içeren ölçek toplam 23 ifadeden oluşmaktadır. Ölçekte yer alan alt boyutlar; paylaşım ihtiyacı (8 madde - örnek ifade: Sosyal medya siteleri sayesinde ortak ilgi ve amaçlara sahip olduğum kişilere ulaşabileceğimi düşünüyorum.), sosyal yetkinlik (6 madde - örnek ifade: Sosyal medya siteleri sayesinde yeni bir kişilik kazandığımı hissediyorum.), sosyal izolasyon (6 madde - örnek ifade: Sosyal medya siteleri yüzünden diğer sosyal aktivitelere yeterince vakit ayıramıyorum.) ve öğretmenlerle ilişkidir (3 madde - örnek ifade: Öğretmenlerimin sosyal medya sitelerinde beni takip etmesi kendimi değerli hissetmemi sağlıyor.). Ölçek alt boyutlarının Cronbach Alpha değerleri sosyal yetkinlik $(\alpha=0.790)$, paylaşım ihtiyacı $(\alpha=0.818)$, öğretmenler ile iletişim $(\alpha=0.789)$, sosyal izolasyon $(\alpha=0.851)$ olarak hesaplanmıştır.

Öğrencilerin yalnızlık algılarının ölçülmesi amacıyla, UCLA Yalnızlık Ölçeği kullanılmıştır. Russell, Peplau ve Ferguson (1978) tarafından geliştirilen ölçek belirli aralıklarla revize edilmiştir (Russell, Peplau ve Cutrona, 1980; Russell, 1996). Demir (1989) tarafindan Türkçeye uyarlanan ölçek 20 ifadeden (örnek ifadeler: Kendimi diğer insanlardan soyutlanmış hissediyorum, İlgilerim ve fikirlerim çevremdekilerce paylaşılmıyor) oluşmaktadır. 4'lü Likert tipinde hazırlanan ölçeğin son versiyonunda 10 ifade ters skorludur. Katılımcıların, UCLA Yalnızlık Ölçeğinden alabileceği yalnızlık puanları 20 ile 80 arasında değişmektedir. Ölçekten alınan 20-34 arasındaki puanlar düşük düzeyli yalnızlık, 35-48 arasındaki puanlar orta düzeyli yalnızlığ göstermektedir. 49 ve üstündeki puanlar ise yüksek yalnızlık düzeyini ifade eder. Yapılan güvenilirlik analizinde Cronbach's Alpha değeri $(\alpha=0.785)$ olarak bulunmuştur. Ankette ayrıca öğrencilerin sosyal medya kullanım şekli ve amaçlarını anlamaya yönelik sorular yer almaktadır.

\section{Verilerin Analizi}

Çalışmanın veri seti SPSS 22 istatistik paket programı kullanılarak analiz edilmiştir. Öncelikle frekans analizi ve çapraz tablolar analizi ile demografik değişkenler incelenmiş, verinin geçerliliğini incelemek için faktör analizi yapılmış ve güvenirliliğini incelemek için Cronbach’s Alpha güvenirlilik analizi yapılmıştır. Faktör analizinde her bir ölçek ayrı olarak faktör analizine tabi tutulmuştur. Faktör analizinde faktör döndürmesi için Varimax tekniği kullanılmıştır. Yapılan analizler sonucunda tüm ölçeklerin orijinal yapısı toplanan veri özelinde desteklenmiştir. Sosyal medya tutum ölçeğinin dört faktörlü yapisı desteklenmiş ve bu dört faktörün toplam varyansı \%58,48’ini açıladığ1 görülmüştür. Yalnızlık ölçeğinin tek faktörlü yapısı desteklenmiş ve bu faktörün toplam varyansı \%56,23’ünü açıkladığ1 görülmüştür.

\section{Bulgular}

Araştırma değisskenlerinin aritmetik ortalama ve standart sapma bulguları Tablo 1'de verilmiştir.

Tablo 1. Arastrma Değgşkenleri Aritmetik Ortalamalar ve Standart Sapmalar

\begin{tabular}{lccc}
\hline Değişkenler & N & Ortalama & Standart sapma \\
\hline Yalnızlık & & 58,75 & 9,52 \\
Sosyal yetkinlik & & 2,55 & 0,87 \\
Paylaşım ihtiyacı & 478 & 3,18 & 0,83 \\
Öğretmen ile iletişim & & 2,66 & 1,12 \\
Sosyal izolasyon & 2,41 & 1,00 \\
\hline
\end{tabular}

Tablo 1'e göre, sosyal medya tutumları alt faktörlerinden sosyal yetkinlik boyutu puan ortalaması 2.55 , paylaşım ihtiyacı alt boyutu ortalaması 3.18 , ögretmenlerle ilişki alt boyutu puan ortalaması 2.66 , sosyal izolasyon alt boyutu puan ortalaması 2.41 'dir. Bu bulgulara göre, öğrencilerin sosyal medya tutumlarından paylaşım ihtiyacı en yüksek ortalamaya sahiptir. Farklı çalışmalarda da paylaşım ihtiyacı en yüksek puanlanan tutum olarak raporlanmıştır (örn. Amaghani, 2016, s. 95; Otrar ve Argın, 2014, s. 9).

Öğrencilerin yalnızlık algısı puan ortalaması (ort.=58.75) öğrencilerin yüksek düzeyde yalnızlık algısına sahip olduklarını göstermektedir. UCLA yalnızlık ölçeği kullanılarak öğrencilerin yalnızlık algısını araştıran çalışmalarda yalnızlık puan ortalamalarının önemli düzeyde farklılaşabildiği görülmektedir. 


\section{GENEL}

Örneğin, yalnızlık puan ortalamaları, Akdeniz Üniversitesi Sosyal Bilimler Meslek Yüksekokulu’ndan 348 öğrencide 66.22 (Seçim, Alpar ve Algür, 2014, s. 207), Gazi Üniversitesi’nde 188 öğrenci üzerinde yapılan bir çalş̧mada 34.55 (Illhan, 2012, s. 2383), Sakarya Üniversitesi Sosyal Hizmet Bölümü’nden 224 öğrenci üzerinde yapılan çalışmada 39.05 (Danış, Yıldız, Tekin ve Alkan, 2017, s. 18), İstanbul'daki 7 ayrı okulda öğrenim gören 617 lise öğrencisinin katıldığı bir çalışmada 36.14 olarak bulunmuştur (Yabanc1, 2019, s. 40). Bu bulgular birlikte değerlendirildiğinde sosyal bağlamın ve durumsal faktörlerin yalnızlı̆̆ farklılaştırmada ki önemine işaret etmektedir.

Öğrencilerin sosyal medya kullanım özellikleri ve amaçlarına ilişkin bulgular Tablo 2'de verilmiştir.

Tablo 2. Sosyal Medya Kullanm Özellikleri ve Amaçlar Tablosu

\begin{tabular}{|c|c|c|c|}
\hline \multicolumn{2}{|c|}{ Sosyal medya kullanım } & \multirow{2}{*}{$\frac{\text { Frekans }\left(f_{i}\right)}{400}$} & \multirow{2}{*}{$\frac{\text { Yüzde (\%) }}{83,7}$} \\
\hline Sosyal medya paylaşım siteleri (Facebook, Instagram & Evet & & \\
\hline vb.) sitelerine üyeliğiniz var mı? & Hayır & 78 & 16,3 \\
\hline \multirow{4}{*}{ Sosyal medyayı ne kadar süredir kullanıyorsunuz? } & 1 yldan az & 58 & 12,1 \\
\hline & $1-2 \mathrm{yll}$ & 92 & 19,3 \\
\hline & $3-4$ y1l & 124 & 25,9 \\
\hline & 4 y1l üstü & 204 & 42,7 \\
\hline \multirow{6}{*}{ Sosyal medya sitelerini kullanım sıklığınız nedir? } & Her gün bir kereden fazla & 277 & 61,6 \\
\hline & Her gün bir kere & 55 & 12,2 \\
\hline & Haftada bir kereden fazla & 43 & 9,6 \\
\hline & Haftada bir kere & 29 & 6,4 \\
\hline & Ayda birkaç kere & 46 & 10,2 \\
\hline & Cevapsiz & 28 & \\
\hline \multirow{4}{*}{$\begin{array}{l}\text { Sosyal medyada günlük ortalama ne kadar zaman } \\
\text { geçiriyorsunuz? }\end{array}$} & 1 saatten az & 155 & 32,4 \\
\hline & $1-3$ saat aras 1 & 188 & 39,3 \\
\hline & 4-6 saat aras 1 & 76 & 15,9 \\
\hline & 6 saat üstü & 59 & 12,4 \\
\hline \multirow{3}{*}{$\begin{array}{l}\text { Sosyal medyayı kullanmaya başladıktan sonra gerçek } \\
\text { hayattaki sosyal çevrenizde değişiklik oldu mu? }\end{array}$} & Azaldı & 62 & 13,0 \\
\hline & Değişmedi & 279 & 58,3 \\
\hline & Artt1 & 137 & 28,7 \\
\hline \multirow{2}{*}{$\begin{array}{l}\text { Paylaşımda bulunma (Fotoğraf, video, müzik, yazı, } \\
\text { konum vb.) }\end{array}$} & Evet & 379 & 79,3 \\
\hline & Hayır & 99 & 20,7 \\
\hline \multirow{2}{*}{ İletişim (Yazışma, sohbet) } & Evet & 413 & 86,4 \\
\hline & Hayır & 65 & 13,6 \\
\hline \multirow{2}{*}{ Eğlence (Oyun, müzik dinleme vb.) } & Evet & 375 & 78,5 \\
\hline & Hayır & 103 & 21,5 \\
\hline \multirow{2}{*}{ Basskalarını takip etme ve takip edilme } & Evet & 363 & 76,0 \\
\hline & Hayır & 115 & 24,0 \\
\hline \multirow{2}{*}{ Kendini ifade etme } & Evet & 307 & 64,2 \\
\hline & Hayır & 171 & 35,8 \\
\hline \multirow{2}{*}{ Sosyalleşme (Gruplara katılma vb.) } & Evet & 302 & 63,2 \\
\hline & Hayır & 176 & 36,8 \\
\hline \multirow{2}{*}{ Bilgi kaynağ1 (Haber takibi, ödev, araştırma vb.) } & Evet & 406 & 85,0 \\
\hline & Hayır & 72 & 15,0 \\
\hline \multirow{2}{*}{ Vakit geçirme } & Evet & 411 & 86,0 \\
\hline & Hayır & 67 & 14,0 \\
\hline \multirow{2}{*}{ Gerçek dünyadan kaçış } & Evet & 138 & 29,0 \\
\hline & Hayır & 340 & 71,0 \\
\hline
\end{tabular}

Tablo-2'ye göre, öğrencilerin \%83.7'sinin Facebook, Instagram gibi sosyal medya paylaşım sitelerine üyeliği bulunmaktadır. Katılımcıların \%42.7'si 4 yılı aşkın süredir sosyal medya araçlarını kullanıyorken, 3-4 yil arası kullananlar \%25.9, 1-2 yil arası kullananlar \%19.3 ve 1 yildan az süredir kullananların oranı ise \%12.1'dir. Öğrencilerden sosyal medya sitelerini kullanım sıklığnız nedir? sorusuna 277'si (\%61.6) "her gün bir kereden fazla", 55’i (\%12.2) "her gün bir kere", 43’ü (\%9.6) "haftada bir kereden fazla", 29’u (\%6.4) "haftada bir kere", 46's1 (\%10.2) "ayda birkaç kere" şeklinde cevap vermişlerdir. Katılımcıların \%73.8'i her gün en az bir kere sosyal medyayı kullanmaktadır. Amaghani ve Akbağ’’n (2018, s. 15) çalışmasında bu oran \%75.6, Otrar ve Argin'ın (2014, s. 4) yürüttüğü araştırmada ise \%56.7 olarak raporlanmışır. Günlük ortalama sosyal medyada geçirilen sürelere ilişkin bulgular ise, 1 saatten az \%32.4, 1-3 saat aras1 \%39.3, 4-6 saat aras1 \%15.9, 6 saat üstü \%12.4 şeklindedir. Buna göre, katllimcıların 
\%87.9’unun günlük ortalama 1 saatten fazla sosyal medya araçlarına zaman ayırmaktadır. Tüm bu bulgular birlikte değerlendirildiğinde, sosyal medyanın bireylerin günlük yaşamının önemli bir parçası haline geldiğini göstermektedir. Diğer taraftan, zamanla daha düşük iyi oluş ve artan yalnızlık algısı ve yalnızlaşma gibi önemli bir riske de işaret etmektedir. Günlük kullanım süreleri psikolojik iyi oluş açısından literatürde önerilen sürelerin (bkz. Hunt vd., 2018, s. 763) üzerindedir. Yoğun sosyal medya kullanımının gerçek iletişim ve sosyal etkileşimin azalmasına bağlı olarak psikolojik iyi oluşu azalttı̆̆ı ve bireyleri yalnızlaştırarak depresif semptomları desteklediği literatürde gösterilmiştir (örn. Teo ve Lee, 2016, s. 351).

Sosyal medya kullanım amaçlarına ilişkin bulgulara göre; katılımcıların \%79.3’ü paylaşım, \%86.4’ü iletişim kurma, \%78.5'i eğlence, \%76’’ başkalarını takip etme ve başkaları tarafından takip edilme, \%64.2'si kendini ifade etme, \%63.2'si gruplara katılma yoluyla sosyalleşme, \%85'i bilgi kaynağ1, \%86's1 vakit geçirme, \%29'u ise gerçek dünyadan kaçış amacına sahip olduklarını vurgulamışlardır. Buna göre, katılımcıların sosyal medya araçlarını kullanma amaçlarında ilk sırada yazışma ve sohbet yoluyla iletişim kurma, vakit geçirme ve bilgi kaynağı olarak kullanma yer almaktadır. Nispi olarak düşük olmakla birlikte, sosyal medyanın \%29 oranında gerçek dünyadan kaçış aracı olarak görülmesi dikkatle incelenmesi gereken bir sonuçtur.

Tablo 3'de değişkenlerin güvenilirlilik değerleri (Cronbach's Alpha) ve değişkenler arası korelasyon katsayıları verilmiştir. Korelasyon tablosu incelendiğinde ilgi çekici bazı değerlerin olduğu görülmektedir.

Tablo 3. Korelasyon Analizi Bulgular

\begin{tabular}{|c|c|c|c|c|c|c|c|c|c|}
\hline \multicolumn{2}{|c|}{ Araştırma değişkenleri } & 1 & 2 & 3 & 4 & 5 & $\overline{6}$ & 7 & 8 \\
\hline \multirow{3}{*}{ 1. Yaş } & Pearson Correlation & & & & & & & & \\
\hline & Sig. (2-tailed) & & & & & & & & \\
\hline & $\mathrm{N}$ & 477 & & & & & & & \\
\hline \multirow{3}{*}{ 2. SM kullanım sıklığ1 } & Pearson Correlation &,$- 399^{* *}$ & & & & & & & \\
\hline & Sig. (2-tailed) & 000 & & & & & & & \\
\hline & $\mathrm{N}$ & 449 & 450 & & & & & & \\
\hline \multirow{3}{*}{$\begin{array}{l}\text { 3. SM günlük kullanım } \\
\text { süresi }\end{array}$} & Pearson Correlation &, $261^{* *}$ &,$- 340^{* *}$ & & & & & & \\
\hline & Sig. (2-tailed) & ,000 & 000 & & & & & & \\
\hline & $\mathrm{N}$ & 457 & 449 & 458 & & & & & \\
\hline \multirow{3}{*}{ 4. Yalnızlık (UCLA) } & Pearson Correlation &,- 033 &,- 079 &,- 017 & {$[0,785]$} & & & & \\
\hline & Sig. (2-tailed) & ,469 & ,096 &, 715 & & & & & \\
\hline & $\mathrm{N}$ & 477 & 450 & 458 & 478 & & & & \\
\hline \multirow{3}{*}{ 5. Sosyal yetkinlik } & Pearson Correlation &, 027 &,$- 140^{* *}$ &, 083 &,$- 138^{* *}$ & {$[0,790]$} & & & \\
\hline & Sig. (2-tailed) &, 564 & ,003 &, 076 & 003 & & & & \\
\hline & $\mathrm{N}$ & 477 & 450 & 458 & 478 & 478 & & & \\
\hline \multirow{3}{*}{ 6. Paylaşım ihtiyacı } & Pearson Correlation &, $092^{*}$ &,- 038 &, $179^{* *}$ &, $148^{* *}$ &, $528^{* *}$ & {$[0,818]$} & & \\
\hline & Sig. (2-tailed) &, 045 & ,419 &, 000 & ,001 &, 000 & & & \\
\hline & $\mathrm{N}$ & 477 & 450 & 458 & 478 & 478 & 478 & & \\
\hline \multirow{3}{*}{ 7. Öğretmen ile iletişim } & Pearson Correlation &,- 011 &, 062 &,- 026 &,- 020 &, $511^{* *}$ &, $405^{* *}$ & {$[0,789]$} & \\
\hline & Sig. (2-tailed) & ,811 & , 188 &, 573 & 662 & ,000 &, 000 & & \\
\hline & $\mathrm{N}$ & 477 & 450 & 458 & 478 & 478 & 478 & 478 & \\
\hline \multirow{3}{*}{ 8. Sosyal izolasyon } & Pearson Correlation & 073 &,- 044 &, $116^{*}$ &,$- 215^{* *}$ &, $340^{* *}$ &, $095^{*}$ &, $280^{* *}$ & {$[0,851]$} \\
\hline & Sig. (2-tailed) & ,109 & ,351 &, 013 &, 000 & ,000 &, 039 &, 000 & \\
\hline & $\mathrm{N}$ & 477 & 450 & 458 & 478 & 478 & 478 & 478 & 478 \\
\hline
\end{tabular}

*Korelasyon .05 seviyesinde anlamli; ** Korelasyon .01 seviyesinde anlamlı; SM : Sosyal medya

Korelasyon analizi bulgularına göre (bkz. Tablo-2), kullanım sıklı̆̆ ile günlük ortalama kullanım süresi arasında istatistiksel olarak anlamlı negatif ilişki $[\mathrm{r}=-0.340, \mathrm{p}<0.01]$ olduğu sonucuna ulaşılmıştır. Öte yandan yaş, sosyal medya kullanım sıklığı ile negatif ilişkili iken $[\mathrm{r}=-0.399, \mathrm{p}<0.001]$, günlük ortalama kullanım süresi ile pozitif ilişkilidir $[\mathrm{r}=0.261, \mathrm{p}<0.01]$. Ayrıca, yaş arttıkça paylaşım ihtiyacı tutumunun daha fazla vurgulandığ1 görülmektedir $[\mathrm{r}=0.092, \mathrm{p}<0.05]$.

Sosyal yetkinlik tutumu ile kullanım sıklığı arasında çok zayıf negatif ilişki $[\mathrm{r}=-0.140, \mathrm{p}<0.01]$ bulunmuştur. Öğrencilerin sosyal yetkinlik tutumu arttıkça sosyal medya kullanım sıklığı azalmaktadır. Sosyal medya tutumlarından paylaşım ihtiyacı ve sosyal izolasyon ile günlük ortalama kullanım süresi arasında istatistiksel olarak anlamlı pozitif korelasyon bulunmuştur. Bu sonuca göre, öğrencilerde paylaşım ihtiyacı ve sosyal izolasyon tutumu güçlendikçe sosyal medyanın günlük ortalama kullanım sürelerinin arttığı sonucuna ulaşılmıştır. 


\section{GENEL}

Sosyal yetkinlik $[\mathrm{r}=-0.138, \mathrm{p}<0.01]$ ve sosyal izolasyon $[\mathrm{r}=-0.215, \mathrm{p}<0.01]$ tutumlar1 ile yalnuzlık algısı arasında negatif ilişki vardır. Paylaşım ihtiyacı tutumu ile yalnızlık arasında ise pozitif korelasyon $[\mathrm{r}=$ $0.148, \mathrm{p}<0.01$ ] bulunmuştur. Bu bulgulara göre, araştırmanın $\mathrm{H} 1, \mathrm{H} 2$ ve $\mathrm{H} 4$ hipotezleri desteklenirken, $\mathrm{H} 3$ hipotezi desteklenmemiştir. Daha yüksek sosyal yetkinlik ve sosyal izolasyon tutumuna sahip öğrenciler daha düşük yalnızlık algısına sahipken, daha yüksek paylaşım ihtiyacına sahip öğrenciler ise daha yüksek yalnızlık algısına sahiptir. Sözü edilen sonuçlar, sosyal medyayı gerçek dünyadan kaçış olarak gören öğrenciler, ilgili değişkenler açısından incelendiğinde daha da anlam kazanmaktadır. Sosyal medyayı gerçek dünyadan kaçı̧ aracı olarak gören öğrencilerin yalnızlık puan ortalaması (ort.=56,64), böyle görmeyen öğrencilerden (ort. $=59,55)$ daha düşüktür $(\mathrm{p}<0.01)$. Bununla birlikte, sosyal medyayı gerçek dünyadan kaçış aracı olarak gören ögrencilerin sosyal izolasyon (ort. $=2,65)$ ve sosyal yetkinlik (ort. $=2,76)$ puanları, böyle görmeyen ögrencilerin puanlarından (sırasıyla, ort. $=2,32$ ve ort. $=2,47$ ) anlamlı olarak daha yüksektir $(\mathrm{p}<0.01)$. Bu bulgular, yalnızlık düzeyi düşük bireylerin kendilerini gerçek sosyal çevrelerinden izole ederek, sanal dünyada sosyalleşme motivasyonlanının daha yüksek olabileceği şeklinde yorumlanabilir.

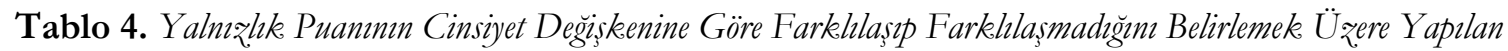
Bağzmsız Grup t-testi Sonuclar

\begin{tabular}{|c|c|c|c|c|c|c|c|}
\hline \multirow{2}{*}{ Puan } & \multirow{2}{*}{ Gruplar } & \multirow{2}{*}{$\boldsymbol{N}$} & \multirow{2}{*}{ A.ortalama } & \multirow{2}{*}{$s s$} & \multicolumn{3}{|c|}{$t$-testi } \\
\hline & & & & & $t$ & $S d$ & $p$ \\
\hline \multirow{2}{*}{ Yalnızlık } & Erkek & 302 & 57,64 & 9,1 & \multirow{2}{*}{-3.368} & \multirow{2}{*}{476} & \multirow{2}{*}{0.001} \\
\hline & Kadın & 176 & 60,65 & 9,94 & & & \\
\hline
\end{tabular}

Tablo 4'e göre öğrencilerin UCLA yalnızlık ölçeğinden aldıkları toplam puanların, cinsiyet değişkenine göre farkl1lık gösterip göstermediğini belirlemek amacıyla yapılan bağımsız grup $\mathrm{t}$-testi sonucunda grupların aritmetik ortalamaları arasındaki farkllık anlamlı bulunmuştur $(\mathrm{p}<.01)$. Kadın ögrencilerin yalnızlık algıları (ort. $=60,65)$ erkeklerin yalnızlı algılarından (ort. $=57,64)$ anlamlı olarak daha yüksektir $(\mathrm{p}<0.01)$. Genellikle çalışmalar erkek öğrencilerin yalnızlık algısının kız öğrencilerden daha yüksek olduğunu (örn. Demir, 1990, s. 121; Le Roux ve Connors, 2001, s. 50; Yıldırım, 2007, s. 68) ortaya koyarken, cinsiyete göre anlamlı farklılık gözlenmeyen araştırmalarda vardır (Danış vd., 2017, s. 19; Jones, Freeman ve Goswick, 1981, s. 45; Wittenberg ve Reis,1986, s. 127).

Tablo 5. Sosyal Medya Tutumlarmm Cinsiyet Değiskeenine Göre Farkhlaşıp Farklilaşmadrğm Belirlemek Üzere Yapulan Bağımsız Grup t-testi Sonuclar

\begin{tabular}{|c|c|c|c|c|c|c|c|}
\hline \multirow{2}{*}{ Puan } & \multirow{2}{*}{ Gruplar } & \multirow{2}{*}{$N$} & \multirow{2}{*}{$A O$} & \multirow{2}{*}{$s s$} & \multicolumn{3}{|c|}{$t$-testi } \\
\hline & & & & & $t$ & $S d$ & $p$ \\
\hline \multirow{2}{*}{ Sosyal yetkinlik } & Erkek & 302 & 2,61 & 0,86 & \multirow{2}{*}{2.184} & \multirow{2}{*}{476} & \multirow{2}{*}{0.029} \\
\hline & Kadin & 176 & 2,43 & 0,86 & & & \\
\hline \multirow{2}{*}{ Paylaşım ihtiyacı } & Erkek & 302 & 3,07 & 0,82 & \multirow{2}{*}{-3.688} & \multirow{2}{*}{476} & \multirow{2}{*}{0.000} \\
\hline & Kadın & 176 & 3,36 & 0,83 & & & \\
\hline
\end{tabular}

Bağımsız grup t-testi sonucunda cinsiyet değişkenine göre, sosyal yetkinlik ve paylaşım ihtiyacı için aritmetik ortalamalar arasındaki farklılık anlamlı bulunmuştur. Sosyal yetkinlik tutumunda, erkeklerin puan ortalaması (ort.=2,61) kadın öğrencilerden (ort.=2,43) daha yüksektir. Aküzüm ve Saraçoğlu $(2017$, s. 813) tarafindan 399 üniversite öğrencisi üzerinde yapılmış olan çalışmada da benzer bir sonuca ulaşılmıştır. Kadın öğrencilerin paylaşım ihtiyacı tutum puanı (ort.=3,36) erkeklerden (ort. $=3,07$ ) anlamlı olarak daha yüksektir $(\mathrm{p}<0.01)$. Benzer şekilde, İstanbul Üniversitesi - Cerrahpaşa Spor Bilimleri Fakültesi'nden 160 ögrenci üzerinde yapılan çalışmada da öğretmenle iletişim ve sosyal izolasyon tutumlarında cinsiyete göre farklılaşma olmazken, sosyal yetkinlik ve paylaşım ihtiyacında farklılaşma olduğu gösterilmiştir (Tükenmez, Güler, Hocaoğlu ve Şahin, 2019, s. 945). Ancak bu çalışmada farklılaşma tam aksi şekilde gerçekleşmiştir. Argin (2013, s. 106-107) tarafindan gerçekleştirilmiş çalışmada öğrencilerin sosyal izolasyon ve sosyal yetkinlik boyutları puanlarının öğrencilerin cinsiyetine göre farklılaştığı ve farklılıkların erkek öğrenciler lehine gerçekleştiği belirlenmiştir.

\section{Tartışma, Sonuç ve Öneriler}

Bu çalışmada sosyal medya tutum alt boyutlarının yalnızlık algısı ile ilişkisi lise ve ön lisans öğrencileri üzerinde araştırılmıştır. Korelasyon bulguları, sosyal yetkinlik tutumu ile yalnızlık arasında olumsuz bağlantı olduğunu göstermektedir. Sosyal yetkinlik tutumunu vurgulayan öğrencilerin yalnızlık alg1sı görece daha düşüktür. Öğrenciler düşük yalnızlık algısına sahip olduklarında sosyal medyanın sosyal yetkinliği artırdığına dair kabulleri güçlenmektedir. Benzer şekilde sosyal izolasyon tutumunun yalnızlık ile negatif 
ilişkili olduğu sonucuna ulaşılmıştır. Yalnızlık algısı düşük öğrenciler sosyal medyanın sosyal izolasyonlarını artırdığını daha fazla vurgulamıştır. Bu durum iki farklı biçimde yorumlanabilir. Birincisi; kendinizi yalnız hissetmiyorsanız sosyal olarak izole olmak için sosyal medyayı bir araç olarak görme olasıllı̆ınız artabilir. İkinci yorum ise; yalnızlık algıları düşük bireyler, sosyal medyanın sosyal izolasyona neden olduğunu daha gerçekçi olarak değerlendirebilir. Sosyal izolasyon tutumunu ölçen ifadeler [sosyal medya siteleri yüzünden diğer sosyal aktivitelere yeterince vakit ayıramıyorum, sosyal medya siteleri yüzünden derslerime yeterli özeni gösteremiyorum, sosyal medya siteleri yüzünden arkadaşlarıma yeterince vakit ayıramıyorum] dikkate alındığında ikinci yorum daha muhtemeldir. Yalnızlık algıları düşük olan öğrencilerin sosyal medyaya ilişkin tutum ya da değerlendirmelerinin daha gerçekçi olabileceği açıtıtır. Bu bağlamda, ilgili kişilerin sosyal medya bağımlıllğının da düşük olduğu görüşünü ispat niteliğinde pek çok araştırmanın varlığına (Yüksel, Çini ve Yasak, 2020, s. 78) rastlamak mümkündür.

$\mathrm{Bu}$ sonuçların tersine paylaşım ihtiyacı yalnızlık ile pozitif ilişkilidir. Yani, paylaşım ihtiyacını vurgulayan öğrencilerin yalnızlık alg1sı daha yüksektir. Al-Saggaf ve Nielsen, (2014, s. 464-465) tarafindan Facebook kullanıcıları üzerinde yapılan çalışma sosyal medya ağlarında çok sayıda paylaşımda bulunmanın yalnızlı̆ı̆n bir göstergesi olabileceğini göstermiştir. Bu çalışmanın sonuçları, yalnızlık hisseden kişilerin Facebook'ta kişisel bilgilerini, ilişki (yani ilişki durumu, cinsiyetimi profilimde göster vb.) ve adres bilgilerini açıklama olasıllğının daha yüksek olduğunu göstermiştir. Kendilerini yalnız hisseden kişilerin bu tip bilgileri paylaşması, diğer insanların kendileri ile iletişime geçmesini kolaylaştırır ve bu durum yalnızlık hissiyle başa çıkmalarında yardımcı olabilir. Diğer taraftan yalnız bireyler, fark edilmek isteyebilir ve kendilerine güven duygusunu geliştirmek için paylaşımda bulunabilir.

$\mathrm{Bu}$ çalışmada, sosyal medya tutumlarından öğretmen ile ilişki alt boyutunun yalnızlık ile ilişkili olmadığı sonucuna ulaşılmıştır. Sosyal medya tutumlarının yalnızlık ile ilişkisini inceleyen sınırlı sayıda çalışma bulunmaktadır (Amaghani ve Akbağ, 2018; Yabanc1, 2019). Araştırmalar, bu iki değişkenin birbiriyle ilişkili olduğuna işaret etmektedir. Ancak, bu çalışmaların büyük bir çoğunluğunda sosyal medya tutumları toplam puan üzerinden değerlendirilmiş, alt boyutların yalnızlık ile ilişkisi gösterilmemiştir. Ayrıca, literatürde sosyal medya kullanımı, amaçları ya da tutumları gibi değişkenlerde ciddi bir kavram kargaşası olduğu görülmektedir. $\mathrm{Bu}$ durum, araştırmalar arasındaki mukayeseyi imkânsız hale getirmektedir.

Çalışmaya katılan öğrencilerin yalnızlık algılarının yüksek olduğu görülmektedir. Ayrıca, öğrencilerin sosyal medya tutum alt boyutlarından puan ortalaması en yüksek olan paylaşım ihtiyacı iken, en düşük puan ortalaması sosyal izolasyona aittir. Bu sonuçlar, yalnızlı algısı artan gençlerde paylaşım ihtiyacının arttı̆̆1 ve sosyal izolasyon seviyesinin azaldığı sonucu ile tutarlıdır.

Sosyal medya kullanım sıklı̆ının günlük ortalama kullanım süresi ile zayıf negatif ilişkili olduğu şeklindeki bulgu, bu iki değişkenin birbirlerinden bağımsız değiş̧kenler olduğunu göstermektedir. Öte yandan, yaş arttıkça sosyal medya kullanım sıklığı azalırken, günlük ortalama kullanım süresi artmaktadır. Bu sonuç, sosyal medya kullanım şeklinin yaşa bağlı olarak değiştiğini göstermektedir. Buna göre, kullanım sıklı̆̆ ile günlük ortalama kullanım süresi arasındaki ilişkide yaş değişkeninin düzenleyici olabileceği söylenebilir. Bu değişkenler arasındaki ilişkileri inceleyen kapsamlı araştırmalar farklı sosyal medya kullanım motivasyonlarının anlaşılmasında yardımcı olabilir.

Sosyal bir varlık olan bireyin davranış ve tutumları yıllar itibariyle, gelişen teknoloji ve günün olağan akışına göre orantısal bir şekilde değişime uğramaktadır. Çocuklar geçmiş yıllarda yaşamsal bilgileri aile ile arkadaşlarından ve okul (akademik) yaşamlarından edinmekteydiler. Toplumsal yaşamın bir sonucu olarak da sosyal grup kanallarından edindikleri bilgiler ve tesis ettikleri iletişim düzeyleri tutum ve davranışlara etki etmekte idi. Ancak günümüzün değişen koşullarında, teknolojinin de ilerlemesi ile birlikte, sosyal medya ve internet ağları, bilgi edinme süreçlerini değişime uğratmakla birlikte, hemen her yaşta popülasyonun olduğu gibi gençlerin de tutumlarını değişimlere uğratma kabiliyetini haizdir.

Günümüzün değişen koşullarına koşut olarak toplumun tüm bireyleri tarafindan sosyal medya haber edinme ve haberleşme maksadı ile kullanılmaktadır. Ayrıca internet araçlarından sosyal medya kullanımı, ülkemizde olduğu gibi dünya üzerinde hemen her coğrafyada artan bir hızla devam etmektedir. Bilhassa, genç yaş popülasyonu üzerinde etkisi artan ve hızla karşıllk bulan ilgili akım, öncelikli olarak lise ve üniversite çağlarındaki gençlerde görülmektedir. Gerçekleştirilen çalışmada, lise ve önlisans düzeyinde ögretim gören gençlerin sosyal medya kullanım alşskanlıkları, sosyal medyayı hangi amaçlar ile ve ne kadar süreler ile kullandıkları araştırılmıştır. Araştırma kapsamında, gençlerin sosyal medya kullanımına dair 
tutumları irdelenir iken öte yandan da yalnızlık olgusuna dair algıları ve ilgili süreç içerisinde ne tür tutumlar geliştirdikleri izlenmeye çalışılmış ve ilgili tutum ve algıların sonuçları irdelenmiştir.

Bilindiği üzere, internet ve sosyal medya mecraları, hemen her yaş popülasyonuna dahil bireyler tarafindan kolay, hızlı, maliyetsiz ve rahat ulaşılabilmektedir. İlgili olumlu yanlarına rağmen sosyal medya araçlarının kontrolü de aynı oranda güç bir durumu ortaya çıkarmaktadır. Sosyal medya ağları ile geçirilen sürelerin uzunluğu ve sosyal bir varlık olan bireylerin, sosyalleşme ihtiyaçlarını yüz yüze iletişimden uzak şekilde sanal biçimde gerçekleştirmeleri sosyalleşme olgusunu aile ve yakın çevrelerinin dışında, sosyal medya araçlarından öğrenmelerine de sebebiyet vermiştir. Kontrol edilmesi gerekli olan bir yapi olarak eleştirilere uğrayan sosyal medya, farklı bir sosyalleşme algısını da günümüze taşımışırı. Sosyalleşme olgusunu aile ve yakın çevreleri yerine sosyal medya araçlarından öğrenen bireyler, asosyal davranışlar sergilemeye meyil etmişlerdir. Sosyalleşmenin karşıtı ve istenmeyen durumu olan asosyalleşme durumu, zamanla hemen her popülasyonda olduğu gibi gençler üzerinde de fiziki ve psikolojik bağlamda birtakım sorunları beraberinde getirmiştir. Sosyal medya tutumları ve yalnızlık algısı çalışması ile kanıtlanan sorunlar, geçmiş yıllarda gerçekleştirilen ve literatür dahilinde yer edinen çalışmaları destekler nitelikte verileri bulgular niteliktedir.

Literatürde yalnızlık çok boyutlu olarak da ele alınmıştır. Örneğin, sosyal ve duygusal yalnızlık olmak üzere iki boyutlu; kozmik, sosyal, kişiler arası ve duygusal yalnızlık olarak dört boyutlu (akt. İlhan, 2012, s. 2378) biçiminde incelenmiştir. Ayrıca, yalnızlık korku veya endişe kaynaklı utangaçlık ve farklı nedenlerle sosyalleşmekten kaçınma kaynaklı olabileceği gibi bilinçli bir tercih de olabilir. Sosyal medya kullanımı ya da tutumları ile yalnızlık arasındaki ilişkinin sağlıklı bir biçimde ortaya konması için yalnızlığın sözü edilen farklı boyutlarını ve motivasyonlarını içeren araştırma modellerine ihtiyaç vardır.

\section{Etik Beyan}

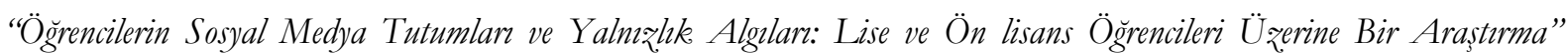
başlığını taşıyan çalışmanın yazım sürecinde bilimsel, etik ve alıntı kurallarına uyulmuş; toplanan veriler üzerinde herhangi bir tahrifat yapılmamış ve bu çalışma herhangi başka bir akademik yayın ortamına değerlendirme için gönderilmemiştir. Gerekli olan etik kurul izinleri Yalova Üniversitesi İnsan araştırmaları Etik Kurulu'nun 04.03.2021 tarih ve 2021/25 sayılı kararı ile alınmıştır.

\section{Kaynakça}

Aküzüm, C. ve Saraçoğlu, M. (2017). Üniversite öğrencilerinin sosyal medyaya ilişkin tutumlarının incelenmesi. Dicle Üniversitesi Ziya Gökalp Ë̈̈tim Fakültesi Dergisi, 32, 803-817.

Al-Saggaf, Y. ve Nielsen, S. (2014). Self-disclosure on Facebook among female users and its relationship to feelings of loneliness. Computers in Human Behavior, 36, 460-468.

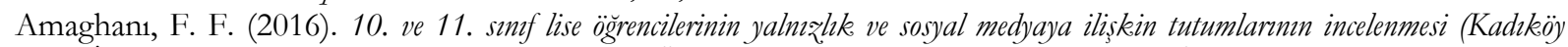
İlçesi örneği) (Yüksek Lisans Tezi). Marmara Üniversitesi Eğitim Bilimleri Enstitüsü, İstanbul.

Amaghani, F. F. ve Akbağ, M. (2018). Gençlerde sosyal medyaya yönelik tutumlar ve yalnızlık: İlişkisel bir inceleme. Gençlik Arasstrmalar Dergisi, 6(15), 5-42.

Argın, F. S. (2013). Ortaokul ve lise ögrencilerinin sosyal medyaya ilişkin tutumlarmn incelenmesi (Yüksek Lisans Tezi). Yeditepe Üniversitesi Sosyal Bilimler Enstitüsü, İstanbul.

Bozkurt, V. (2018). Sosyal medya kullanan gengler arasinda bencillik ve yalnıそhk. Türkiye'nin Yüzyllı ve Geleceği Uluslararası Gençlik Sempozyumu Tebliğler Kitabı. 4-5 Ekim 2018. İstanbul.

Chou, C. ve Hsiao, M. C. (2000). Internet addiction, usage, gratification, and pleasure experience: The Taiwan college student's case. Computers and Education, 35, 65-80.

Danıs, M. Z., Yıldız, R., Tekin, H. E. ve Alkan, P. (2017). Sosyal hizmet öğrencilerinin yalnızlık düzeyleri ve bunu etkileyen faktörler: Sakarya örneği. Yalova Sosyal Bilimler Dergisi, 7(14), 9-22.

Demir, A. (1989). UCLA Yalnızlık Ölçeği'nin geçerlik ve güvenirliği. Psikoloji Dergisi, 7(23), 14-18.

Demir, A. (1990). Üniversite ögrencilerinin yalmı̨hk düreylerini etkileyen baž etmenler (Doktora Tezi). Hacettepe Üniversitesi Sosyal Bilimler Enstitüsü, Ankara.

Donnelly, E. ve Kuss, D. J. (2016). Depression among users of social networking sites (SNSs): The role of SNS addiction and increased usage. Journal of Addiction and Preventive Medicine, 1(2), 107-112.

Forest, A. L. ve Wood, J. V. (2012). When social networking is not working: Individuals with low self-esteem recognize but do not reap the benefits of self-disclosure on Facebook. Psychological science, 23(3), 295-302.

Griffin, J. (2010). The lonely society? London: Mental Health Foundation.

Hunt, M. G., Marx, R., Lipson, C. ve Young, J. (2018). No more FOMO: Limiting social media decreases loneliness and depression. Journal of Social and Clinical Psychology, 37(10), 751-768.

İlhan, T. (2012). Üniversite öğrencilerinde yalnızlık: cinsiyet rolleri ve bağlanma stillerinin yalnızlı̆̆ı yordama güçleri. Kuram ve Uygulamada Egitim Bilimleri, 12(4), 2377-2396. 
Jones, W. H.. Freeman, J. A. ve Goswick, R. A. (1981). The persistence of loneliness: Self and other determinants. Journal of Personality, 49, 27-48.

Kalpidou, M., Costin, D. ve Morris, J. (2011). The relationship between Facebook and the well-being of undergraduate college students. CyberPsychology, Behavior, and Social Networking, 14(4), 183-189.

Kim, J., LaRose, R. ve Peng, W. (2009). Loneliness as the cause and the effect of problematic internet use: The relationship between internet use and psychological well-being. Cyberpsychology and Behavior, 12(4), 451-455.

Kross, E., Verduyn, P., Demiralp, E., Park, J., Lee, D. S., Lin, N., ... ve Ybarra, O. (2013). Facebook use predicts declines in subjective well-being in young adults. PloS one, 8(8), e69841.

Kubey, R. W., Lavin, M. J. ve Barrows, J. R. (2001). Internet Use and Colligate Academic Performance Decrements: Early Fidings. Journal of Communiation, 51, 366-382.

Le Roux, A. ve Connors, J. (2001). A cross-cultural study into loneliness amongst university students. South African Journal of Psychology, 31(2), 46-52.

Otrar, M. ve Argin, F. S. (2014). The examination of the students' attitudes towards social media within the context of habits. Journal of Research in Education and Teaching, 3(3), 1-13.

Otrar, M. ve Argın, F. S. (2015). Öğrencilerin sosyal medyaya ilişkin tutumlarını belirlemeye yönelik bir ölçek geliştirme çalışması. Ë̈̆tim ve Ögretim Arastırmalar Dergisi, 4(1), 391-403.

Pittman, M. ve Reich, B. (2016). Social media and loneliness: Why an Instagram picture may be worth more than a thousand Twitter words. Computers in Human Behavior, 62, 155-167.

Roshoe, B. ve Skomski, G.G. (1989). Loneliness Among Late Adolesents. Journal Of Adolesence, 24, 947-955.

Russell, D. W. (1996). UCLA Loneliness Scale (Version 3): Reliability, validity, and factor structure. Journal of Personality Assessment, 66(1), 20-40.

Russell, D., Peplau, L. A. ve Cutrona, C. E. (1980). The revised UCLA Loneliness Scale: Concurrent and discriminant validity evidence. Journal of personality and social psychology, 39(3), 472.

Russell, D., Peplau, L. A. ve Ferguson, M. L. (1978). Developing a measure of loneliness. Journal of personality assessment, 42(3), 290-294.

Savc1, M. ve Aysan, F. (2016). Relationship between impulsivity, social media usage and loneliness. Educational Process: International Journal, 5(2), 106-115.

Seçim, Ö. Y., Alpar, Ö., ve Algür, S. (2014). Üniversite öğrencilerinde yalnızlık: akdeniz üniversitesinde yapılan ampirik bir araştırma. Elektronike Sosyal Bilimler Dergisi, 13(48), 200-215.

Shaw, L. H. ve Gant, L. M. (2002). In defense of the internet: The relationship between internet communication and depression, loneliness, self-esteem, and perceived social support. CyberPsychology \& Behavior, 5, 157-171.

Song, H., Zmyslinski-Seelig, A., Kim, J., Drent, A., Victor, A., Omori, K. ve Allen, M. (2014). Does Facebook make you lonely?: A meta analysis. Computers in Human Behavior, 36, 446-452.

Steers, M. L. N., Wickham, R. E. ve Acitelli, L. K. (2014). Seeing everyone else's highlight reels: How Facebook usage is linked to depressive symptoms. Journal of Social and Clinical Psychology, 33(8), 701-731.

Tandoc Jr, E. C., Ferrucci, P. ve Duffy, M. (2015). Facebook use, envy, and depression among college students: Is facebooking depressing?. Computers in Human Behavior, 43, 139-146.

Teo, W. J. S. ve Lee, C. S. (2016). Sharing Brings Happiness?: Effects of Sharing in Social Media Among Adult Users. In International Conference on Asian Digital Libraries (pp. 351-365). Springer, Cham.

Tromholt M. (2016). The Facebook experiment: quitting facebook leads to higher levels of well-being. Cyberpsychol. Behav. Soc. Netw, 19, 661-666

Tükenmez, A., Güler, C., Hocaoğlu, M. ve Şahin S. (2019). Genç bireylerin sosyal medya tutumlarının incelenmesi. Journal Of Social, Humanities and Administrative Sciences, 5(20), 942-947.

Twenge, J. M. (2018). i-Nesli (Çev: O. Gündüz). İstanbul: Kaknüs Yayınları.

Verduyn, P., Lee, D. S., Park, J., Shablack, H., Orvell, A., Bayer, J., ... ve Kross, E. (2015). Passive Facebook usage undermines affective well-being: Experimental and longitudinal evidence. Journal of Experimental Psychology: General, 144(2), 480-488.

Wittenberg, M. T. ve Reis, H. T. (1986). Loneliness, social skills, and social perception. Personality and Social Psychology Bulletin, 12, 121-130.

Yabanc1, C. (2019). Lise ögrencilerinin sosyal medyaya iliskin tutumlar ile narsisizm ve yalnıఇlı düzeyleri arasindaki iliskinin incelenmesi (Yüksek Lisans Tezi). Bursa Uludağ Üniversitesi Eğitim Bilimleri Enstitüsü, Bursa

Yang, S. C. ve Tung, C. J. (2007). Comparison of Internet addicts and non-addicts in Taiwanese high school. Computers in human behavior, 23(1), 79-96.

Yıldırım, M. (2007). Şiddete başvuran ve başvurmayan ergenlerin yalnıそlık düzeyleri ve akeran baskısı düzeyleri açısından incelenmesi (Yüksek Lisans Tezi). Çukurova Üniversitesi Sosyal Bilimler Enstitüsü, Adana.

Young, K. S. ve Roger, R. C. (1998). The relationship between depression and internet addiction. Cyberpsychology and Behavior, 1, 25-28.

Yüksel, M. Y., Çini, A. ve Yasak, B. (2020). Genç yetişkinlerde sosyal medya bağımlılığı, yalnızlık ve yaşam doyumu arasındaki ilişkinin incelenmesi. Atatürk Üniversitesi Ką̧ım Karabekir Eğitim Fakültesi Dergisi, 40, 66-85. 


\section{EXTENDED ABSTRACT}

Social media, which is widespread among younger generations, continues to grow. According to the We are social 2nd Quarter report, $49 \%$ of the world's population is social media users. According to the same report, the most used social media platforms are Facebook, Youtube and Instagram, respectively. $56 \%$ of Facebook users and 64\% of Instagram users are in the 18-34 age range. Loneliness has become one of the most important pandemics in the digitalized world. The problem of loneliness also persists in societies where social media use is at the highest level (Griffin, 2010; Twenge, 2018).

Studies show that individuals who spend their time in the virtual world are more alone in their real life (eg Kubey, Lavin, \& Barrows, 2001; Shaw, \& Gant, 2002). As the time spent in the virtual world increases, the time spent on face-to-face relationships and real social connections decreases. This causes social isolation and increases loneliness in individuals (Chou, \& Hsiao, 2000). Similarly, Kim, LaRose and Peng (2009) stated that virtual environments distract individuals from real social contexts and strengthen the perception of loneliness. Social media use is also associated with psychological well-being and depressive symptoms Hunt et al., 2018; Tromholt, 2016).

The rapid growth of social media networks in recent years has created a great opportunity for relationship development by allowing people to connect with others by sharing their thoughts and experiences. Social media networks can be thought of as an important resource for people to establish social relationships. However, the aforementioned research results show that social media use can increase social isolation of individuals and undermine their well-being.

One of the important debates in the literature is the direction of the relationship between social media use and loneliness. More depressed or lonely individuals are more likely to use social media to connect with others. Young and Roger (1998) emphasizes that loneliness and social isolation move individuals away from the real world and approach virtual environments.

Findings to be obtained from studies examining the relationship between social media and loneliness can contribute to the deep understanding of the phenomenon of loneliness of individuals, despite the increasing opportunities of interpersonal connection due to the development of social media tools. In this study, it is aimed to examine the relationship between social media attitudes and loneliness on students. Perceptions of loneliness may increase the likelihood of individuals to adopt some attitude or behavioral strategies. A study conducted on adolescents showed that adolescents with low levels of loneliness are more likely to use behavioral strategies such as being included in social groups and see online as a tool to cope with loneliness (Roshoe, \& Skomski, 1989).

Social media attitude scale developed by Otrar and Argin $(2014 ; 2015)$ was used in the study. The scale consists of 23 statements and 4 sub-dimensions. The sub dimensions of the scale; the need for sharing is social competence, social isolation and relationship with teachers. UCLA Loneliness Scale, developed by Russell, Peplau and Ferguson (1978) and adapted to Turkish by Demir (1989), was used to measure students' perceptions of loneliness. The collected data were analyzed with the help of SPSS 22 program. The four-factor structure of the social media attitude scale was supported and it was seen that these four factors explain the total variance of $58.48 \%$. The single factor structure of the loneliness scale was supported and it was seen that this factor explained $56.23 \%$ of the total variance.

Social competence average of social media attitudes sub-dimensions is 2.55 , sharing need subdimension average is 3.18 , relationship with teachers sub-dimension average score is 2.66 , social isolation sub-dimension average is 2.41 . According to these findings, students' need to share their social media attitudes has the highest average. The average score of students' perception of loneliness $($ mean $=58.75)$ shows that students have a high level of loneliness perception.

There is a negative relationship between social competence $[\mathrm{r}=-0.138, \mathrm{p}<0.01]$ and social isolation $[\mathrm{r}$ $=-0.215, \mathrm{p}<0.01]$ and the perception of loneliness. A positive correlation was found between the attitude of need to share and loneliness $[\mathrm{r}=0.148, \mathrm{p}<0.01]$. According to these findings, while the H1, H2 and H4 hypotheses of the study were supported, the H3 hypothesis was not.

Correlation findings show that there is a negative connection between social competence attitude and loneliness. The loneliness perception of the students who emphasized social competence attitude was relatively lower. When students have a low perception of loneliness, their acceptance that social media increases social competence becomes stronger. Similarly, it was concluded that social isolation attitude was 
negatively related to loneliness. Students with low perception of loneliness emphasized more that social media increased their social isolation. This situation can be interpreted in two different ways. First one; If you don't feel alone, you may be more likely to see social media as a tool to be socially isolated. The second comment is; Individuals with low perceptions of loneliness can more realistically evaluate that social media causes social isolation. The second interpretation is more likely when the statements measuring the social isolation attitude are taken into account. Contrary to these results, the need for sharing is positively associated with loneliness.

In this study, it was concluded that the relationship with the teacher sub-dimension of social media attitudes is not related to loneliness. There are a limited number of studies examining the relationship between social media attitudes and loneliness (eg Amaghani, \& Akbağ, 2018; Foreign, 2019). Studies indicate that these two variables are interrelated.

It is seen that the loneliness perception of the students participating in the study is high. In addition, while the social media attitude sub-dimensions of the students are the highest mean score, the sharing need is the lowest, while the lowest average score belongs to social isolation. These results are consistent with the result that the need for sharing increases and the level of social isolation decreases in young people whose loneliness perception increases.

The finding that the frequency of social media use is weakly negatively related to the average daily usage time indicates that these two variables are independent variables. On the other hand, as the age increases, the frequency of social media usage decreases, while the average daily usage time increases. This result shows that the use of social media changes with age. Accordingly, it can be said that the age variable may regulate the relationship between the frequency of use and the average daily duration of use. Extensive research examining the relationships between these variables can be helpful in understanding different social media use motivations. 